\title{
SPATIAL AND TEMPORAL PATTERN OF RICE YIELD GROWTH \\ IN ASIAN COUNTRIES FROM 1961 to 2016: AN EXPLORATORY \\ ECONOMETRIC ANALYSIS
}

\author{
Debabrata Mukhopadhyay ${ }^{1}$ \\ *Corresponding author E-mail: debu1641975@yahoo.co.in
}

A R T I C L E I N F O
Original Article
Received: 14 September 2020
Accepted: 11 January 2021
doi:10.5937/ekoPolj2101023M
UDC 330.34.014 -026.23:633.1
8"1961/2016"(292.5)

Keywords:

rice production, yield, structural break, technology innovations, environmental challenges

JEL: C22, Q10, Q18

\begin{abstract}
A B S T R A C T
The present paper attempts to find out the spatial and temporal movement of rice yield in twelve countries in Asia which is its lifeline over the period 1961 to 2016 by following Bai-Perron multiple structural break tests. The results based on endogenous multiple structural break analysis show that many of these countries passed through several phases of acceleration and deceleration in rice yield over this period The results also demonstrate that except Japan, all the twelve countries considered in our study experienced at least one structural break in rice yield at level during the period 1961 to 2016. The acceleration phases of rice yield growth observed mostly during 1970's and 1980's are resulted from improved technological innovations in agriculture whereas deceleration phases observed in the last two decades are mainly caused by environmental challenges on rice production. Cross country yield gaps have been showing declining trend since early 80's.
\end{abstract}

(C) 2021 EA. All rights reserved.

\section{Introduction}

Agricultural development is still an important economic policy commitment to reduce poverty and for ensuring sustainable food security in many parts of the developing world. Rice is the most important staple crop in South and South-East Asia (John \& Fieding, 2014). Although rice (Oryza sativa species) was domesticated in Asia thousands of years ago, it is still the leading cereal in human food systems (Trébuil, 2004).

About $87 \%$ of global production of rice takes place in Asia in the year 2018 as per the latest report of the Food and Agricultural Organization (FAO) of the United Nations(UN). Rice plays a major role in global food security, as it is the staple food for over half of the world's population (Bandumula, 2017). Asia is the centre of global food security with more than half of the world's population and one-third of global

1 Debabrata Mukhopadhyay, Ph.D., Professor, Department of Economics, West Bengal State University, Kolkata, India, PIN-712126. E-mail: debu1641975@yahoo.co.in, ORCID ID (https://orcid.org/0000-0002-3159-8928) 
hungry and poor (Monika, 2013). Recent research in food and nutrition science shows that eating rice makes general health better and still is considered as 'grain of life'. The recent data also show that $15 \%$ of the global farm area and almost a quarter of the world's cereal croplands are occupied by rice lands. More than 200 million rice farmers are involved in this production. This is one of the most important human activity on earth. Its importance is also evident from the fact that rice became the first-ever agricultural commodity to be declared 'Crop of the Year' in the year 1966 by the UN.

During the mid-sixties, the largely agricultural economies of Asia were failing to produce sufficient food to feed the region's rapidly rising populations (FAO Rice Conference, 2004). Asia, once a net exporter of food, the domain of some of the world's lushest rice bowls and wheat lands, home of some of the world's most skilled and industrious farmers, was a food-deficit region, literally dependent on the West to stay alive (Davies, 1967). However, there are two integral major challenges - for now and well into the future - involving rice in Asia. The first is the ability of economies to meet their national and household food security needs with a declining natural resource base, two of the critical resources being water and land. Secondly, - as has been stated so eloquently by the United Nations as one of its eight Millennium Development Goals (www.undp.org/ mdg) - the eradication of extreme poverty and hunger. Rice is so central to the lives of most Asians that any solution to global poverty and hunger must include research that helps poor Asian farmers reduce their risks and earn a decent profit while growing rice that is still affordable to poor consumers (FAO Rice Conference, 2004).

Several studies have shown that global crop production needs to double by 2050 to meet the projected demands from rising population, diet shifts, and increasing biofuels consumption. (Ray et al. 2013). As a result, despite showing an overall surplus in production, consumption or trade of rice, situations in future decades may be affected. Three major kinds of cereals namely, rice, wheat and maize take up the largest areas under cultivation and yield the highest quantities of output which are predominantly used for food and animal feed production. More than $50 \%$ of world daily caloric intake is derived directly from rice consumption (Awika,2011), and this goes to $70 \%$ for the Asian countries. For many years rice has remained a staple food and a cultural identity for a large segment of the Asian countries. Millions of people around the globe depend on rice as the bulk of their daily diet (Elert, 2014)). While addressing the issue of long term movement of rice production across the ten Asian countries, it is observed that most of the Asian counties experienced a structural change in rice production growth in the 1970s and/or 1980s and started to experience slowdown since 1990s (Mukhopadhyay, 2019).

With a total harvested area of approximately 167 million hectares, producing more than 782 million tons annually in the year 2018. Nearly 678 million tons of rice are grown in Asia. But, nearly a fourth of the Asian population is still poor and has a considerable unmet demand for rice. It is in these countries that rice consumption will grow faster(FAO). Despite rice being deeply rooted in cultures and identities of Asian countries, 'rice as self' for Japanese in his famous book, however, these countries differ 
in terms of changing perspective vis-à-vis overall economic focus (Ohnuki-Tierney, 1994). Recent crop yield growth in China has been slow following a county-level crop production data between 1980 and 2010 from eastern and middle China and analyzed rice, wheat and maize yield in five major farming systems of China's cereal production (Li et al. 2016). It is observed that the centre of cereal production has shown a tendency to move towards northern China (Tong et al.,2003; Liu et al., 2009). Japan has also been exhibiting deceleration in yield growth of rice production in recent times along with shrinking of the area under cultivation as their focus has shifted towards rapid industrialization and urbanization. Countries like Cambodia, Nepal, Myanmar still being agrarian have been looking on yield growth for accelerating rice production.

The FAO and the World Bank have identified eight broad classification of farming systems which have been further categorized into 70 farming systems across six developing regions of the world (Dixon, 2012). Among these six regions, two regions namely South Asia and East Asia-Pacific are our central focus. It may be noted that there exists heterogeneity within each farming system in South Asia and East Asian countries for rice production. However, within each farming system prevailing in a region/country understanding the needs of those living in that system are crucial for finding out proper strategies/practices to escape out from poverty and hunger. Despite presence of eleven farming systems in Asia, rice-wheat system is dominant in South Asia and lowland rice farming is the major farming system in East Asia. There are some stylized facts about Asia's rice economy. First of all, at the farming household level, a large proportion of production is self-occupied i.e., marketable surplus is very insignificant. Secondly, rice can be produced in extremely ecological conditions from large and flat coastal plains to mountainous terraces. Next, the production of rainfed lowland rice accounts for a quarter of the total rice-growing areas. Lastly, Soil degradation is a critical issue in most of the farming systems of the region. For instance, in the Rice-Wheat Farming System which is a dominant system in South Asia's rice production, where intensive cultivation and unbalanced fertiliser applications have led to a deterioration in soil structure and fertility, which need some immediate solutions.

Against this backdrop, the present paper attempts to find out the spatial and temporal movement of rice yield( output per hectare cultivated area) in twelve countries ${ }^{2}$ in Asia over the period 1961 to 2016. This study also investigates the presence of structural change in rice-yield over this period by following Bai-Perron multiple structural break tests published in the years 1998,2001 and 2003 for each of the twelve countries which is an important and pertinent issue for understanding the role of technology versus institutions in the country specific perspective. The study also examines whether land productivity of rice i.e., rice yield spread have narrowed over time across these countries through technology spill over by following conventional measures of dispersion standard deviation and coefficient variation.

2 Bangladesh, Cambodia, China, India, Indonesia, Japan, Myanmar, Nepal, Pakistan, Philippines, Thailand and Vietnam. 


\section{Materials and methods}

The data on area(in hectare), production (in tonnes) and yield(hectagram/hectare) are taken from the FAOSTAT of the Food and Agricultural Organization of the UN (http:// www.fao.org/faostat/en/\#data/QC) for the period 1961 to 2016. Assuming y as the crop yield, $A$ as area under cultivation and $\mathrm{Y}$ as output, then $\mathrm{y}=\mathrm{Y} / \mathrm{A}$, implying the growth of output is the sum growth of area and yield in accounting terms. In our analysis, the growth over 1961 to 2016 has been considered.

We now consider the following semilogarithmic equation for each twelve country to determine structural break in rice yield by following Bai-Perron Sequential-F test, for the period 1961 to 2016 (Bai \& Perron(1998); Bai \& Perron (2001); Bai \& Perron (2003)). The estimated growth rate are thus obtained ( $\beta$ coefficient $)$.These estimates enable us to understand variation in estimated growth rates across these nations.

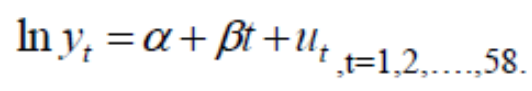

$\alpha:$ Intercept

$\beta$ : Growth coefficient

$u_{t}:$ Error term

Now, it is evident that productivity or yield differ across the Asian countries. Therefore, whether differences are narrowing down over time is pertinent to investigate. We, then, apply an exploratory analysis in terms of inequality measures such as standard deviation(sd) and coefficient of variation(cv). Considering $\mu_{t}$ is the mean of the logarithm(natural) of the rice yield of all twelve Asian countries at time $t$ and $\sigma_{t}$ is the standard deviation of these values at time $t$. Then, $C V_{t}$ defined as $C V_{t}=\frac{\sigma_{t}}{\mu_{t}}$ , is the coefficient of variation of these values at time $t$. We compare such measures of disparities in crop yield like $C V_{t}$ and $\sigma_{t}$ at different time points across the Asian countries. Declining values of these measures indicate lowering of regional disparities in rice yield.

All econometric computations have been carried out by using the econometric software Eviews 9.

\section{Results and Discussions}

We now discuss the empirical results in this section. The movement of rice yield for all the selected countries has been presented in figure 1 below. As shown in table 1 below in the year 2016, China produced 211 Million metric tonnes(MMT) of rice followed 
by India with 159 MMT. As such, in rice production, twelve Asian countries contribute more than $90 \%$ in the world. Two countries China and India together have $50 \%$ and $30 \%$ shares in world production and area of cultivation, respectively. However, in terms of output growth and yield growth, China has better performance compared to India during the period 1961 to 2016 . However, China has been experiencing very slow growth in cropped area in recent times. Again, in terms of present yield ( $\mathrm{kg} / \mathrm{hectare})$ for rice crop, China is ahead of India. Indonesia has notable performance in enhancing output growth by increasing both productivity as well as increasing cropped area.

Figure 1. Movement of Rice yield of 12 Asian countries during 1961 to 2016

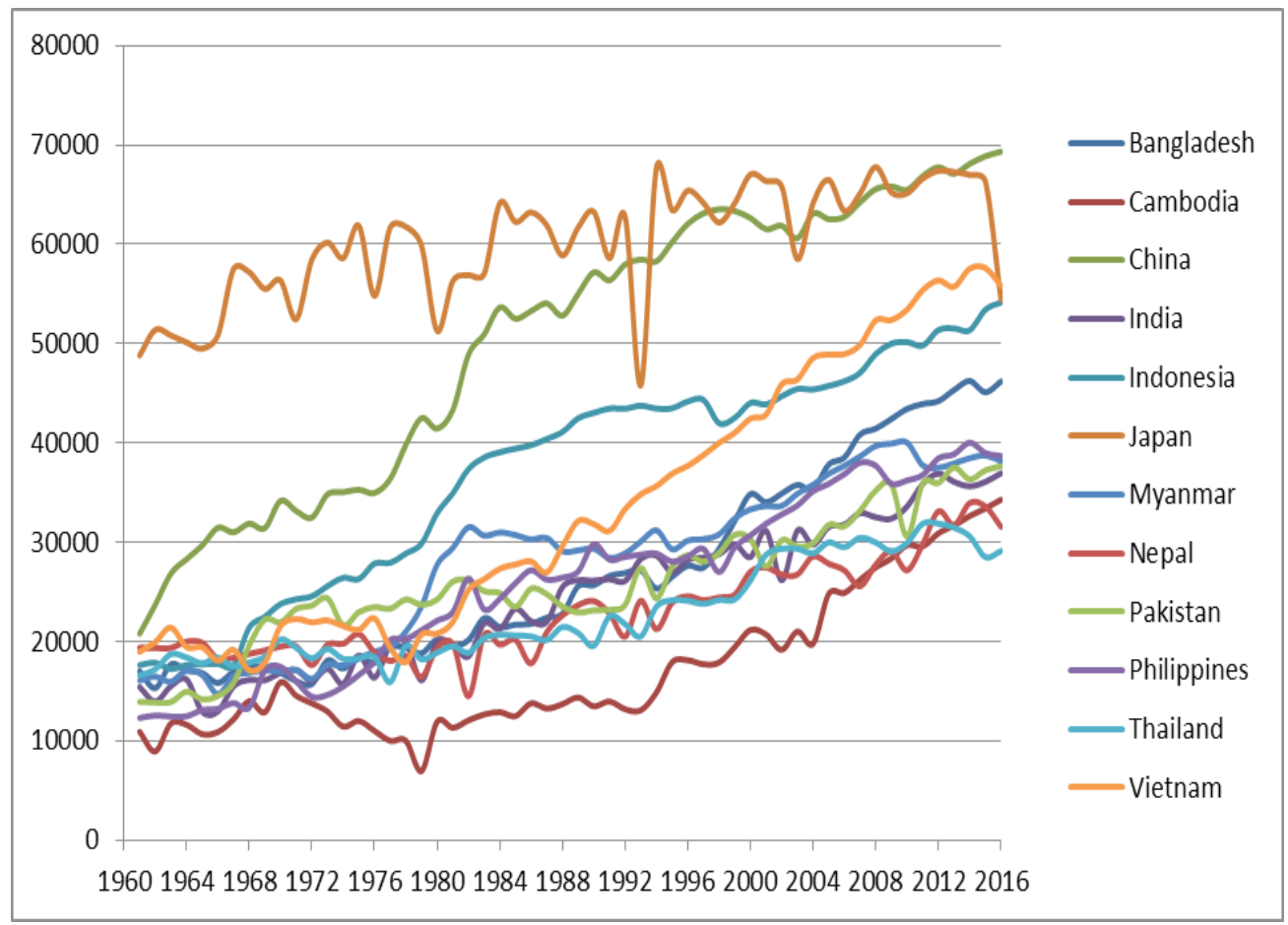

Source: FAOSTAT

Table 1. Rice Production, yield and area of cultivation in twelve Asian Countries in 2016

\begin{tabular}{|c|c|c|c|}
\hline Country & Production(tonnes) & Area (hectare) & Yield per hectare(in kg) \\
\hline Bangladesh & 52590000 & 11000809 & $4618.8 \mathrm{~kg}$ \\
\hline Cambodia & 9827001 & 2908564 & $3427.7 \mathrm{~kg}$ \\
\hline China & 211090813 & 31019837 & $6932.2 \mathrm{~kg}$ \\
\hline India & 158756871 & 43190000 & $3695 \mathrm{~kg}$ \\
\hline Indonesia & 77297509 & 15156000 & $5414.8 \mathrm{~kg}$ \\
\hline Japan & 10055000 & 1479000 & $5438.8 \mathrm{~kg}$ \\
\hline Myanmar & 25672832 & 6723986 & 3818.1 \\
\hline
\end{tabular}




\begin{tabular}{|c|c|c|c|}
\hline Country & Production(tonnes) & Area (hectare) & Yield per hectare(in kg) \\
\hline Nepal & 4299079 & 1362908 & $3154.3 \mathrm{~kg}$ \\
\hline Pakistan & 10412155 & 2724000 & $3764.9 \mathrm{~kg}$ \\
\hline Philippines & 17627245 & 4556043 & $3869 \mathrm{~kg}$ \\
\hline Thailand & 25267523 & 9340007 & 2911.8 \\
\hline Vietnam & 43437229 & 7734722 & $5581 \mathrm{~kg}$ \\
\hline
\end{tabular}

Source: FAOSTAT

As the table 2 given below shows that for most of the countries except Indonesia and Pakistan who experienced 2.201\% and 2.60\% in area under cultivation of rice production, respective, rice production growth has been caused more by yield growth compared to area growth, we now compare the yield growth of these countries.

In terms of average growth of rice yield during the period 1961 to 2016, China experienced highest growth of $4.245 \%$ followed by Philippines experiencing 3.901\%. India has exhibited a moderate yield growth of $2.539 \%$, however, Japan experienced only $0.208 \%$. Seven countries namely, Bangladesh, Cambodia, China, Indonesia, Pakistan, Philippines and Vietnam achieved more than 3\% growth in rice yield. Again, average growth of area under rice cultivation was less than $1 \%$ for most of the countries. Japan experienced a negative growth in are under rice cultivation during this period. It may be pointed out in this context that China, the largest producer of rice on earth has experienced a very low growth of area at $0.267 \%$.

Table 2. Average growth of rice production, yield and area under cultivation during 1961 to

\begin{tabular}{|l|c|c|c|}
\hline \multicolumn{1}{|c|}{ Country } & $\begin{array}{c}\text { Average Yield } \\
\text { growth(\%) }\end{array}$ & $\begin{array}{c}\text { Average Area } \\
\text { growth(\%) }\end{array}$ & $\begin{array}{c}\text { Average Production } \\
\text { growth(\%) }\end{array}$ \\
\hline Bangladesh & 3.12 & 0.540 & 4.81 \\
\hline Cambodia & 3.888 & 0.605 & 5.7 \\
\hline China & 4.245 & 0.267 & 5.501 \\
\hline India & 2.539 & 0.445 & 3.578 \\
\hline Indonesia & 3.768 & 2.201 & 9.812 \\
\hline Japan & 0.208 & -1.006 & -0.687 \\
\hline Myanmar & 2.503 & 1.056 & 5.011 \\
\hline Nepal & 1.141 & 0.459 & 1.89 \\
\hline Pakistan & 3.101 & 2.260 & 9.383 \\
\hline Philippines & 3.901 & 0.787 & 6.378 \\
\hline Thailand & 1.374 & 0.957 & 2.708 \\
\hline Vietnam & 3.532 & 1.146 & 6.959 \\
\hline
\end{tabular}

Source: Author's own calculation based on FAOSTAT data

Comparing average production growth across these countries establish that Indonesia achieved highest growth in rice production with $9.812 \%$ during the last 55 years followed by Pakistan of $9.383 \%$. This growth in these two countries have been possible 
due to remarkable progress achieved in terms of bringing more area under cultivation. But for other except which experienced a negative overall growth of $-0.687 \%$, for all other countries yield has contributed mainly to cause high growth in rice production.

We now report the changes in yield growth in different sub-periods for different countries by following Bai-Perron multiple structural break tests. The results are presented in Table 3 and 4 below. The results on multiple structural break tests due to Bai-Perron are presented in table 3. The results show that except Japan, all the twelve countries considered in our study experienced at least one structural break in rice yield at level during the period 1961 to 2016. Countries namely, Cambodia, India, Nepal and Philippines have exhibited single structural change as the results show based on Sequential-F test of Bai-Peron. These break years are 1976, 1988, 1983 and 1977, respectively. Again, Bangladesh, Myanmar, Pakistan and Thailand experienced two structural break points during this period in rice yield. China, Indonesia and Vietnam have passed though several changes in their rice yield starting from late 1960's. The earliest structural break year in this study is 1969 as observed in China, Indonesia and Pakistan. The year 1988 was another important break as observed by India, Myanmar and Pakistan. Most of the other break years were observed in 1970's and 1980's. These break years are related with technological applications adopted in the countries and the sustainability of those changes coupled with ecological factors such as soil fertility, water management etc.

After determining structural break in rice yield for these countries during our study period, we now present the estimated rice yield growth for different relevant subperiods of these countries following the methodology stated in the previous section. Estimated growth results are presented in table 4. The results show that countries like Cambodia, China, Indonesia, Pakistan and Vietnam have experienced over 3\% yield growth in rice production in some phases of our study period. For instance, Cambodia experienced $3.265 \%$ yield growth in rice production on a sustainable basis for the period 1976 to 2016. China has experienced a very high growth over 5\% in rice yield for a small span 1961 to 1968. Indonesia has observed 3.197\% growth in rice yield for the period 1969 to 1981 . Pakistan experienced high growth at $3.745 \%$ in rice yield during a small span of 1961 to 1968. India has observed a structural break in rice yield growth in 1988 and exhibited moderate growth throughout the period of our analysis. After experiencing negative growth in rice yield in first two phases of this long span, Vietnam has shown a remarkable progress by passing through an acceleration with 3\% growth during 1981 to 2000. These astonishing growth rates are related to technological innovations adopted in agriculture by these countries through are resulted from the gradual expansion of acreage under irrigation and improved high-yielding rice varieties along with use of chemical fertilizer and pesticides. However, these same countries have also experienced several phases of deceleration in rice yield growth before or after acceleration phase. Some of these deceleration phases particularly during the last two decades are caused by environmental challenges as 'new' constraints for rice production. The other most important limiting factor influencing annual production potential is draught, and is 
usually associated with an erratic or intermittent rainfall pattern which leaves crops dry for periods of weeks at a time. The rice varieties grown in Southeast Asia are very sensitive to drought stress,

It may further be noted that in recent times Bangladesh and Cambodia are experiencing over $2 \%$ yield growth of rice production where many other countries are passing through deceleration in yield growth for rice crop with less than 1\%. For instance, during 20012016 in our study period China and Thailand were experiencing $0.877 \%$ and $0.262 \%$ growth in rice yield, respectively. Some of these deceleration phases particularly during the last two decades are caused by environmental challenges as 'new' constraints for rice production. The major ecological challenges in rice production are climate change, natural resource management, biodiversity and sustainability.

Table 3. Structural break in rice yield of Asian Countries during 1961-2016

\begin{tabular}{|l|c|l|}
\hline \multicolumn{1}{|c|}{ Country Name } & $\begin{array}{c}\text { No. of Structural Break under } \\
\text { Bai-Perron Test }\end{array}$ & \multicolumn{1}{c|}{ Break Years } \\
\hline Bangladesh & 2 & 1971,1999 \\
\hline Cambodia & 1 & 1976 \\
\hline China & 3 & $1969,1982,2001$ \\
\hline India & 1 & 1988 \\
\hline Indonesia & 3 & $1969,1982,1998$ \\
\hline Japan & 0 & ------------- \\
\hline Myanmar & 2 & 1979,1988 \\
\hline Nepal & 1 & 1983 \\
\hline Pakistan & 2 & 1969,1988 \\
\hline Philippines & 1 & 1977 \\
\hline Thailand & 2 & 1974,2001 \\
\hline Vietnam & 3 & $1970,1981,2004$ \\
\hline
\end{tabular}

Source: Author's calculations based on FAOSTAT data

Note: The results are determined using sequential-F test statistics of Bai-Perron multiple break tests and using 0.15 trimming point and 5\% significance level.

Table 4. Estimated growth rates in rice yield of Asian Countries during 1961-2016

\begin{tabular}{|c|c|c|}
\hline Country Name & Sub-period & Estimated yield growth(\%) \\
\hline \multirow{3}{*}{ Bangladesh } & $1961-1970$ & 0.004 \\
& $1971-1998$ & 2.140 \\
& $1999-2016$ & 2.199 \\
\hline \multirow{2}{*}{ Cambodia } & $1961-1975$ & 1.810 \\
& $1976-2016$ & 3.265 \\
\hline \multirow{2}{*}{ China } & $1961-1968$ & 5.783 \\
& $1969-1981$ & 2.518 \\
& $1982-2000$ & 1.386 \\
& $2001-2016$ & 0.877 \\
\hline \multirow{2}{*}{ India } & $1961-1987$ & 1.772 \\
& $1988-2016$ & 1.329 \\
\hline
\end{tabular}




\begin{tabular}{|c|c|c|}
\hline Country Name & Sub-period & Estimated yield growth(\%) \\
\hline \multirow{3}{*}{ Indonesia } & $1961-1968$ & 1.641 \\
& $1969-1981$ & 3.197 \\
& $1982-1997$ & 1.119 \\
& $1998-2016$ & 1.361 \\
\hline Japan & $1961-2016$ & 0.435 \\
\hline \multirow{2}{*}{ Myanmar } & $1961-1978$ & 1.219 \\
& $1979-1987$ & 2.270 \\
& $1988-2016$ & 1.329 \\
\hline \multirow{2}{*}{ Nepal } & $1961-1982$ & -0.005 \\
& $1983-2016$ & 1.526 \\
\hline \multirow{2}{*}{ Pakistan } & $1961-1968$ & 3.745 \\
& $1969-1987$ & 0.677 \\
& $1988-2016$ & 1.796 \\
\hline \multirow{2}{*}{ Philippines } & $1961-1976$ & 2.315 \\
& $1977-2016$ & 1.632 \\
\hline \multirow{2}{*}{ Thailand } & $1961-1973$ & 0.917 \\
& $1974-2000$ & 1.344 \\
& $2001-2016$ & 0.262 \\
\hline \multirow{2}{*}{ Vietnam } & $1961-1969$ & -1.652 \\
& $1970-1980$ & -1.180 \\
& $1981-2000$ & 3.018 \\
& $2001-2016$ & 1.560 \\
\hline
\end{tabular}

Source: Author's estimation carried out using a Semilogarithmic model (1) following least squares method under break based on Bai_Perron Sequentially determined break tests

We present the results on trend of productivity spread across these countries by using the figures 2 and 3 below. The cross sectional standard deviations of the logarithm(natural) of rice yield for 12 Asian countries over the period 1961 to 2016 has been presented in Figure 2. This shows a clear declining trend since 1982 after showing some phases of upward trend during first two decades. For instance the values of standard deviations were $0.372,0.532$ and 0.265 in the years 1961,1979 and 2016, respectively. The coefficient of variation, which is a relative measure of dispersion, also shows downward movement as presented in Figure 3. Its value has reduced from 0.038 in 1961 to 0.025 in 2016. These figures are indicating that rice yield gaps are reducing across these countries in South and South East Asia. 
Figure 2. Standard Deviation of rice yield(Productivity) of 12 Asian Countries from 1961 to 2016

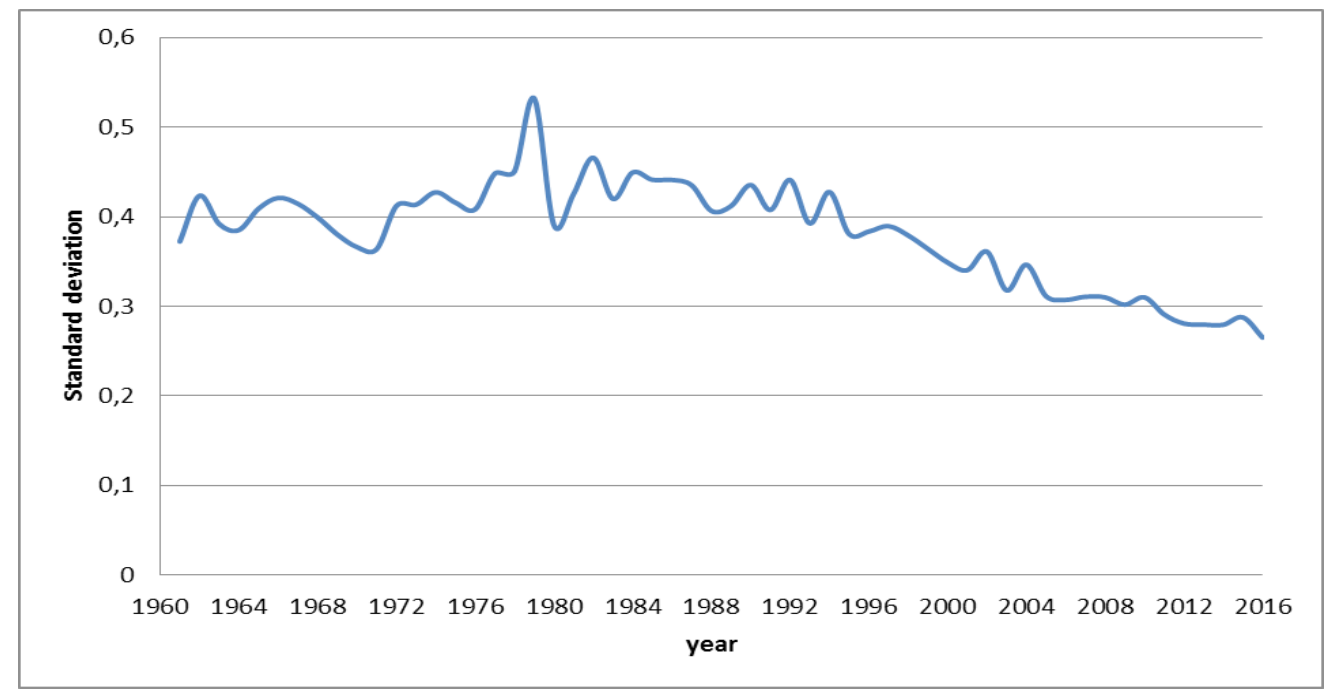

Source: Author's calculations based on FAOSTAT data

Figure 3. Coefficient of variation of rice yield(Productivity) of 12 Asian Countries from 1961 to 2016

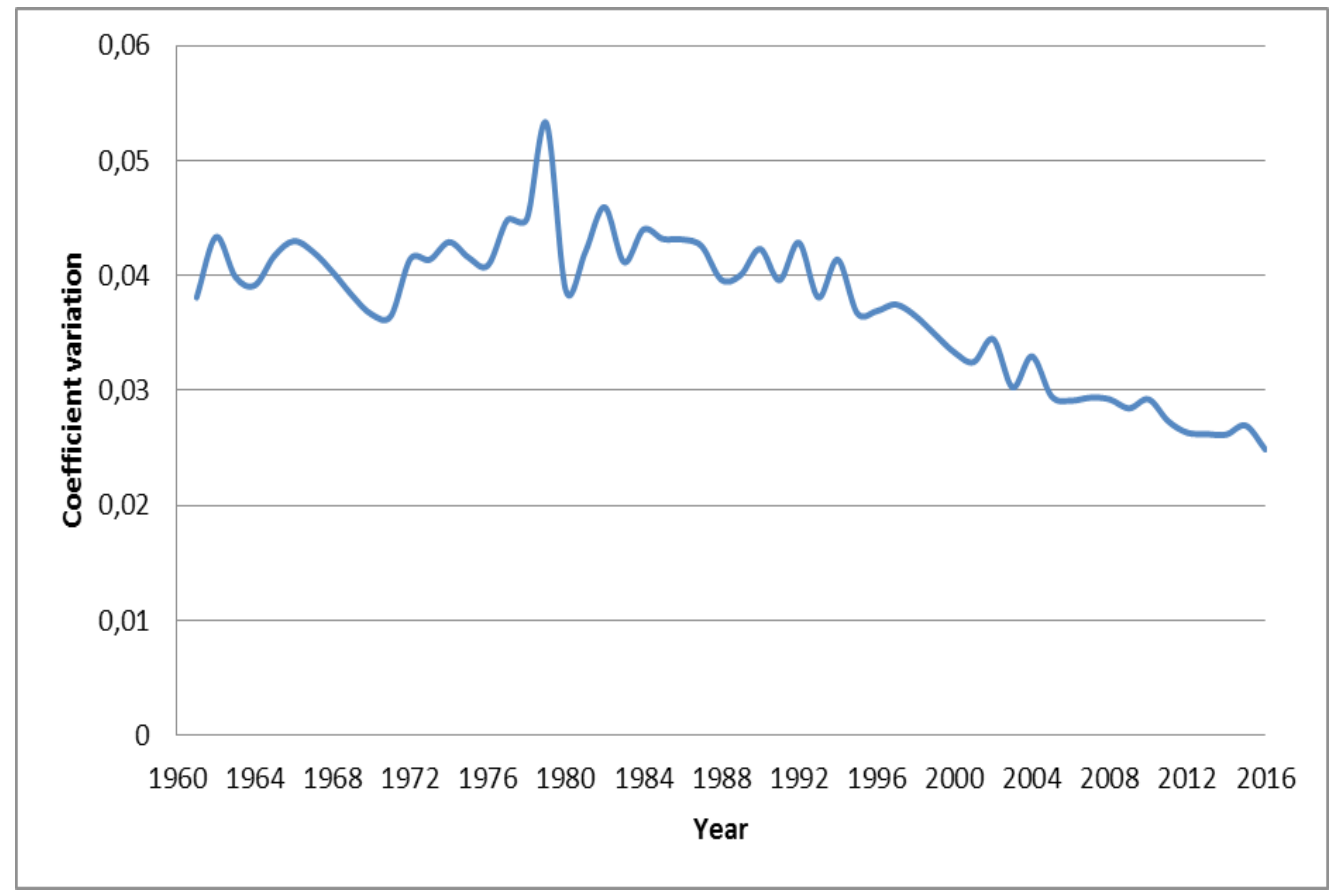

Source: Author's calculations based on FAOSTAT data 
It becomes clear from the above analysis that the production of rice for the major Asian countries have been contributed by yield growth rather than the slow expansion of acreage. Again, during this long period, several changes including technology, institutions and ecological factors have led to structural change in yield growth for these countries.

There have been both phases of acceleration as well as a deceleration in growth experienced by the major rice producers of the world. Thus it is interesting to understand whether yield gaps among these countries have declined over time of our study period indicating convergence of productivity across the countries.

\section{Conclusions}

At the initial level, some econometric exercise based on the identity (i.e., growth of production is the sum of the growth of area and yield) that for most of the Asian countries, the Rice bowl of the World Economy that technology-led yield growth has mainly contributed to feeding 3.5 billions of global population. Exhaustive and comprehensive country-level studies have been carried out to determine the period and sustenance of this rice yield growth for 12 countries in South and South-East Asia over the period 1961 to 2016 . The spatial movement of technology spillover led to declining yield gaps across these countries over time are also addressed using conventional absolute and relative measures of dispersions.

The results show based on endogenous multiple structural break analysis that many of all the twelve countries of our study except Japan have passed through several phases of acceleration and deceleration as far as the temporal movement of rice yield is concerned. Moreover, the applications of technology, policy decisions and ecological limitations in terms of soil fertility, availability of water resources have played a significant role in understanding these phases of acceleration and deceleration in this important crop yield the country. It is also further understood that technology and policy innovations must follow proper coordination to promote crop yields and the sustainable use of agricultural resources to maintain food security in the region.

The policies should consider both the ecological and environmental concerns faced by the major rice producing countries of Asia in order to address the food security problem of increasing population that may arise in view of deceleration of yield growth in recent times. Except, Bangladesh no major rice producing coutry has exhibited yield growth of over $2 \%$ in the last two decades. China has experienced only $0.877 \%$ yield growth during the period 2001 to 2016.

A strategy for the future would be to further strengthen the two-pronged approach of increasing productivity in favourable environments while developing rice technologies that have minimal adverse effects on the resource base of fragile environments (IRRI, 2003).

\section{Conflict of interests}

The authors declare no conflict of interest. 


\section{References}

1. Awika, J.M. (2011). Major Cereal Grains Production and Use around the World. ACS Symposium Series, 11-13. https://doi.org/10.1021/bk-2011-1089.ch001

2. Bai, J., \& Perron, P. (1998). Estimating and Testing Linear Models with Multiple Structural Changes. Econometrica, 66(1), 47-78. https://doi.org/10.2307/2998540

3. Bai, J., \& Perron, P. (2001). Multiple and Structural Change Models: A Simulation Analysis, Columbia University Press.

4. Bai, J., \& Perron, P. (2003). Computation and Analysis of Multiple Structural Change Model. Journal of Applied Econometrics, 18, 1-22. https://doi.org/10.1002/jae.659

5. Bandula, N. (2017). Rice Production in Asia: Key to Global Food Security. Proc. Natl. Acad. Sci., India, Sect. B Biol. Sci, 88(4), 1323-1328. https://doi.org/10.1007/ s40011-017-0867-7

6. Davies, D. (1967). Empty rice bowls. Far Eastern Economic Review Year Book, 19-34.

7. Dixon, J., Gulliver, A., Gibbon, D., \& Hall, M. (2012). Farming systems and poverty. FAO.

8. Elert, E. (2014). Rice by the Numbers: A Good Grain. Nature, 514(7524), 50-61. https://doi.org/10.1038/514s50a

9. FAOSTAT, Retrieved from http://www.fao.org/faostat/en/\#data/QC (July 22, 2020).

10. FAO (2004). Proceedings of the FAO Rice Conference.

11. IRRI (2003). IRRI's environmental agenda. Unpublished draft document.

12. John, A., \& Fielding, M. (2014). Rice production constraints and 'new' challenges for South Asian smallholders: insights into de facto research priorities. Agriculture \& Food Security, 3. https://doi.org/10.1186/2048-7010-3-18

13. Li, X., Liu, N., You, L., Ke, X., Liu, H., \& Huang, M. (2016). Patterns of Cereal Yield Growth across China from 1980 to 2010 and Their Implications for Food Production and Food Security. PLoS ONE, 11(7). https://doi.org/10.1371/journal. pone. 0159061

14. Liu, Y., Wang, J., \& Guo, L. (2009). The spatial-temporal changes of grain production and arable land in China. Scientia Agricultura Sinica, 42(11), 42694274.

15. Monika, B.D. (2013). Food security in Asia: challenges, policies and implications. International Institute for Strategic Studies(IISS), London.

16. Mukhopadhyay, D. (2019). Structural break in rice production: A study with rice production. International Journal of Food and Agricultural Economics, 7(1), 4761. https://doi.org/10.22004/ag.econ.283882

17. Ohnuki-Tierney, E. (1994). Rice As Self, Princeton University Press.

18. Ray, D.K., Ramankutty, N., Mueller, N.D., West, P., \& Foley, J. (2012). Recent Patterns of crop yield growth and stagnation. Nature Communications, 3. https:// doi.org/10.1038/ncomms2296 
19. Trébuil, G. (2004). Rice production systems in Asia: The constant presence of an essential cereal on a continent in mutation Geo-agronomist, Management of renewable resources and environment research unit (Green), Environments \& Societies Department, Cirad, Montpellier, France. Co-Author with M. Hossain of "Le Riz: enjeux écologiques et économiques" published in 2004 by Editions Belin, Paris.

20. Tong, C., Hall, C.A.S., \& Wang, H. (2003). Land use change in rice, wheat and maize production in China (1961-1998). Agriculture Ecosystems \& Environment, 95(2), 523-536. https://doi.org/10.1016/S0167-8809(02)00182-2 